\title{
Enhancing Power Coefficient of a Wind turbine Using Diffuser Augmentation in Combination with Convergence
}

\author{
G. Venkaiah., Dr. B. Sreenivasa Reddy and Dr. A. Venkata Satyanarayana \\ 1 (Mechanical Engineerig, G. Pulla Reddy Engineerig College (Autonomous) /J NTU Anantapur , India) \\ 2 (Mechanical Engineerig, G. Pulla Reddy Engineerig College (Autonomous) /J NTU Anantapur, India)
}

\begin{abstract}
Now a day, horizontal axis wind turbines play key role, in the field of power generation. But, the cost of power generation becomes high, when compared with power generation by other methods. In the present work the emphasis is focused on increasing the conversion efficiency of a wind turbine. The combination of convergent nozzle and diffuser has been fabricated as a part of the work and carried out experiments in the following manner.

- By placing a convergent nozzle at the inlet of wind turbine.

- By placing diffuser at the outlet of wind turbine.

- By using the combination of convergent nozzle and divergent nozzle

The power coefficient of the turbine is determined at various angle of attack in the range of $0^{\circ}$ to $90^{\circ}$.

Keywords: Power Coefficient, Betz limit

Subject Classification: Wind Energy Conversion

\section{Introduction}

European country U.K has been extracting $22.5 \%$ of their power needs from wind. Number of wind mills are installed over the bank of river Thames of length $2000 \mathrm{Km}$. Whereas India possessing a vast coastal track of length $7500 \mathrm{Km}$ could not able to produce at least $10 \%$ of nation's needs. Indian wind energy Association (IWEA) has estimated that with the current level of technology, the on shore potential for utilization of wind energy for electricity generation is of the order of $65000 \mathrm{MW}$ [7]. Hence the present work is focused to enhance the conversion ability at the best. In the present paper various research works related to enhance the power coefficient are mentioned. But in the present work, and its usefulness in wind energy conversion is demonstrated.
\end{abstract}

\section{Problem Identification}

We know the Our country India is potentially strong in wind energy with a huge coastal length more than $7000 \mathrm{Km}$. Wind energy conversion can still become ease with such a huge potential. But statistically, we are not extracting more than $5 \%$ of nations demand. Why? The main reason may be due to poor conversion efficiency. Here discussed wind turbine model using diffuser augmentation in combination with a convergent nozzle.

\subsection{Litarature Review}

The diffuser augmented wind turbines gives high power coefficient. In the design of DAWT, optimum design of diffuser is used. The DAWT produces more energy. The reason is that the diffuser at out let of the turbine controls the flow rate of air, producing sub-atmospheric pressure. The low static pressure induces greater mass flow through the turbine design of the same diameter. The power produced by diffuser augmented wind turbine is twice, when compared to conventional wind turbine [1][3].

\subsection{Objectives}

- Power coefficient enhancement

- The fabrication of diffuser and convergent nozzle

- To compare the performance of the mill under various modifications.

\subsection{Experimental Set Up}

The follow photographs Figure1, Figure 2 illustrated fabrications of diffuser and convergent nozzle. Nozzle at inlet of wind mill and diffuser at out let of wind mill. The diffuser at out let of the turbine controls the flow rate of air, produce sub-atmospheric pressure. The low static pressure induces greater mass flow through the turbine design of the same diameter. And also convergent nozzle gives high mass flow rate of air. 


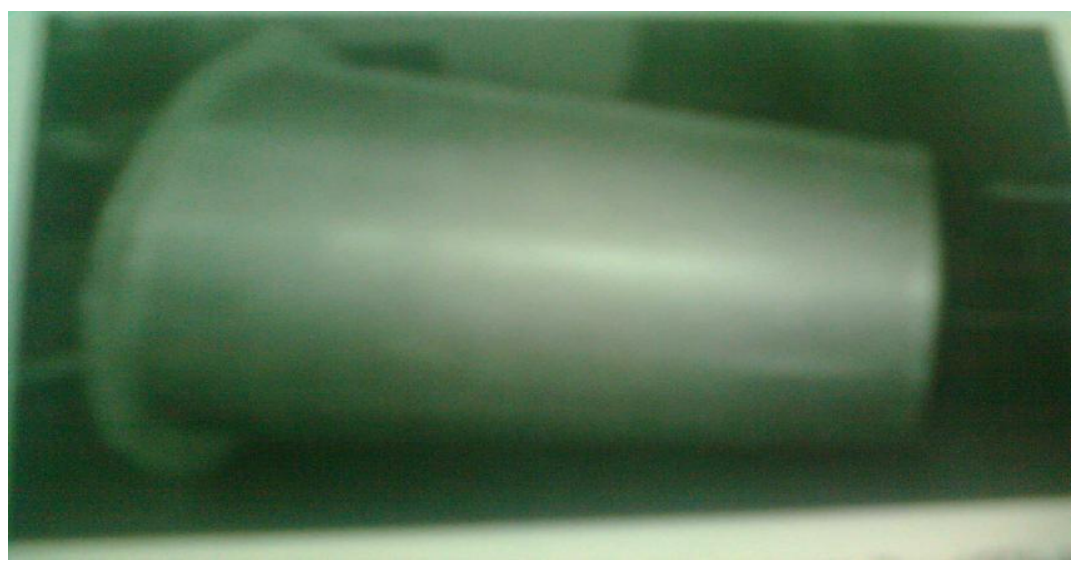

Figure1: Convergent Nozzle

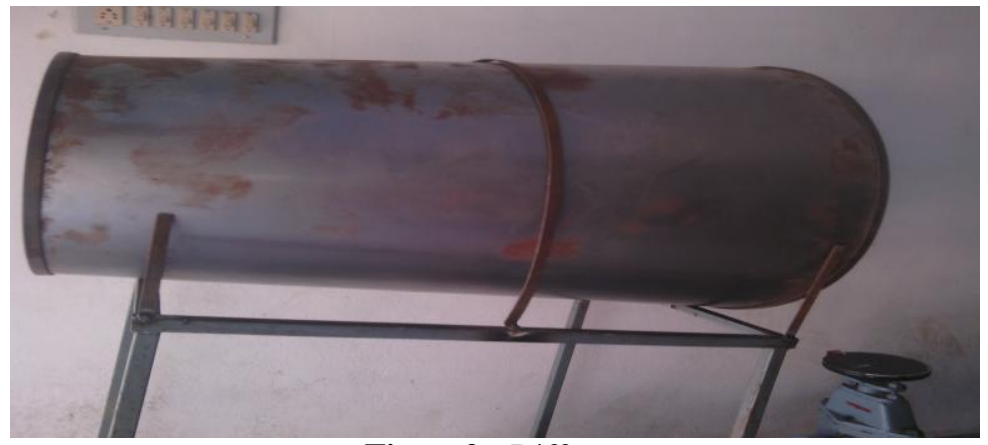

Figure2: Diffuser

\subsection{Fabrication Of Convegent Nozzle And Diffuser}

Step1: An convergent nozzle is fabricated with diameters $60 \mathrm{~cm}$ at inlet and $45 \mathrm{~cm}$ at outlet. Step2: The fabrication of diffuser with diameters $45 \mathrm{~cm}$ at inlet and $74.3 \mathrm{~cm}$ at outlet.

\section{Wind Tunnel And Lab Model Wind Turbine}

For conducting the experiment constant wind velocity is needed. It is obtained by using a wind tunnel in the following Figure It is driven with the blower. Horizontal axis wind mill is best suited power generation. Wind mill consists of 3 numbers of aerofoil bladed each of length $0.34 \mathrm{~m}$. weighed 500 grams.. The photographic diagram of wind tunnel is shown in Figure 3. The photographic representation of wind turbine using diffuser augmentation in combination with a convergent nozzle is shown in Figure 4.

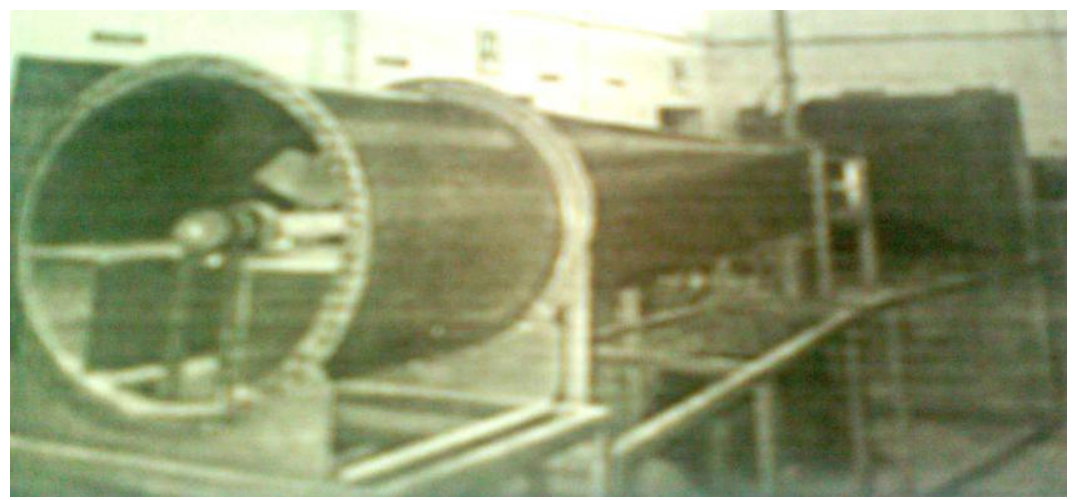

Figure3: Wind Tunnel 


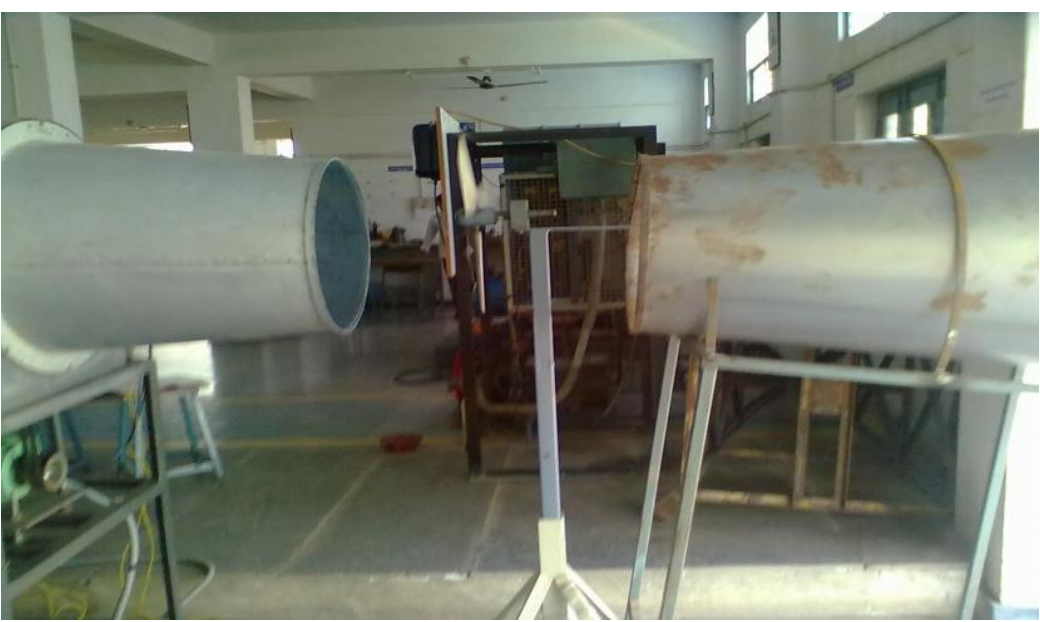

Figure4: Wind Turbine And Using Diffuser Augmentation In Combination With A Convergent Nozzle

\subsection{Instruements Used}

Anemometer: To measure wind velocity, rotating disc type anemometer of range up to $25 \mathrm{~m} / \mathrm{sec}$ is used. The device is kept in a direction perpendicular to the wind velocity to knowledge the velocity of air. The rotations of rotating disc are calibrated into $\mathrm{m} / \mathrm{sec}$.

\section{Results And Discussion}

The experiment is conducted at the angle of attack of 45 degrees to the wind direction. The lab model wind mill is not facilitated to generate power. But from wind laws, the ability of power extraction can be determined. The diffuser at out let of the turbine controls the flow rate of air, produce sub-atmospheric pressure. The low static pressure induces greater mass flow through the turbine design of the same diameter. And also convergent nozzle gives high mass flow rate of air.

\subsection{Equationsused For Power Calculation}

(i) Power available with wind $\mathbf{P a}=\mathbf{0 . 5} \rho * \mathbf{A} * \mathbf{V i}^{\mathbf{3}}$

Where, $\rho$ is the density of the air in $\mathrm{kg} / \mathrm{m} 3$.

$\mathrm{A}$ is the swept area of windmill in $\mathrm{m} 2$

$\mathrm{Vi}$ is the inlet velocity of wind in $\mathrm{m} / \mathrm{s}$

(ii) Producible power $\mathbf{P e}=(\mathbf{1} / \mathbf{4 g c}) *(\mathbf{V i}+\mathbf{V o}) *\left(\mathbf{V i}^{2}-\mathbf{V o}^{2}\right) * \rho * \mathbf{A}$

(no generator loss)

Where Vi is the inlet velocity of wind

Vo is the exit velocity of the wind from rotor

\subsection{Effect Of Power Coefficient}

The power coefficient of the lab model wind mill is 0.1711 under no generator loss. It increases to 0.411 through when used both diffuser augmentation and a convergent nozzle. It is give the high coefficient of power compared to other modification power coefficients. Angle of attack is high at $45^{\circ}$, bellow readings taking at $45^{\circ}$ of wind turbine within every module.

\begin{tabular}{|l|l|l|l|}
\hline Modification & Power available in watts & Producible Power in watts & Theoretical Power coefficient \\
\hline No modification & 70.2 & 12.01 & 0.1711 \\
\hline Only diffuser & 70.2 & 15.896 & 0.226 \\
\hline Only convergent nozzle & 355.8 & 120.52 & 0.3392 \\
\hline $\begin{array}{l}\text { Both diffuser and } \\
\text { convergent nozzle }\end{array}$ & 355.8 & 142.69 & 0.411 \\
\hline
\end{tabular}

Assumptions:

(i) No generator loss

(ii) Power fluctuation may vary the cut in speed. 


\subsection{Power Coefficients With Respect To Various Modifications}

Various modifications are stated bellow.

$\mathrm{Mo}=$ No modification

M1=by placing diffuser at outlet of wind turbine

M2= by placing convergent nozzle at inlet of wind turbine

M3= by placing convergent nozzle at inlet and diffuser at outlet of wind turbine

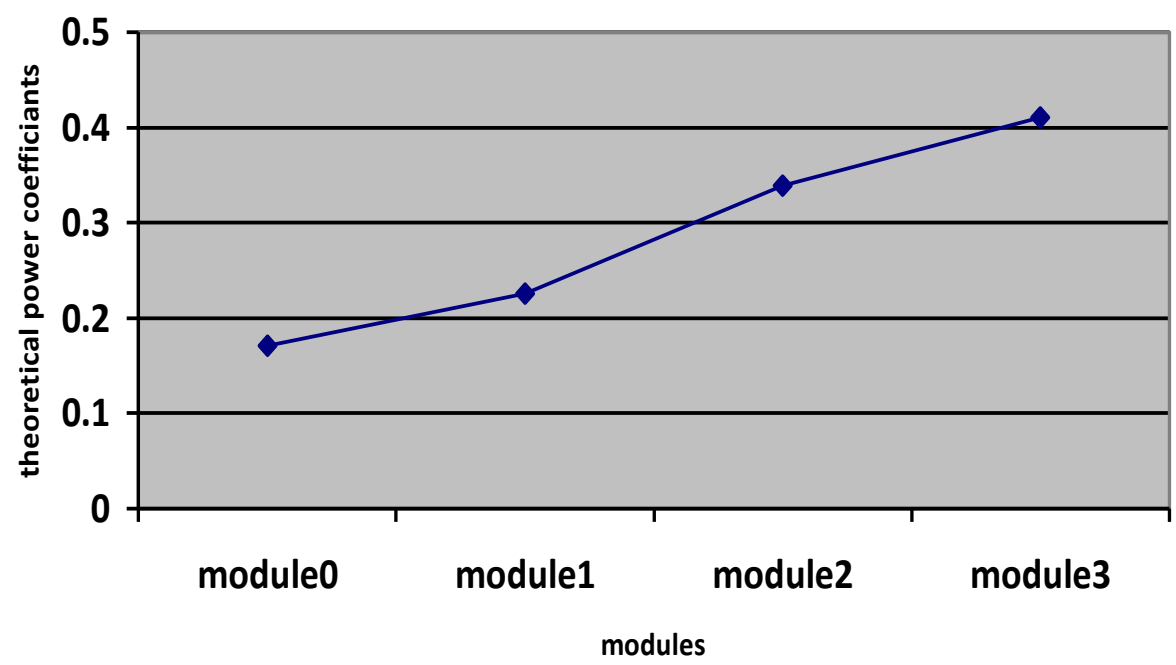

Figure 5: Power Coefficient vs Various Modifications

As shown in above graph M3 gives the high coefficient of power compare to M0, M1, M2. M3 gives coefficient of power 0.411, power available is $355.8 \mathrm{KW}$, Power extractable is $142.69 \mathrm{KW}$. Photographic diagrams of both (Diffuser augmentation+ convergent nozzle) as shown bellow.

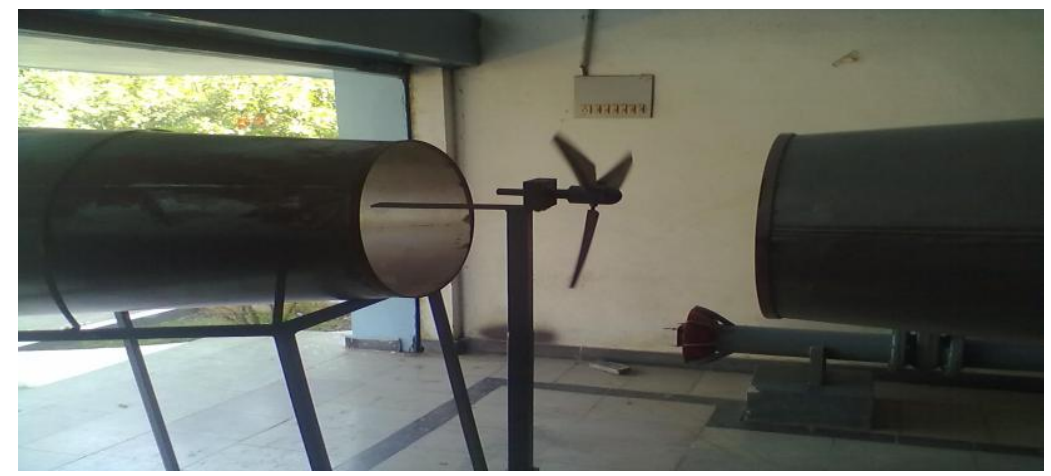

Figure6: Right Side View Of Diffuser Augmentation And Combination With Convergence

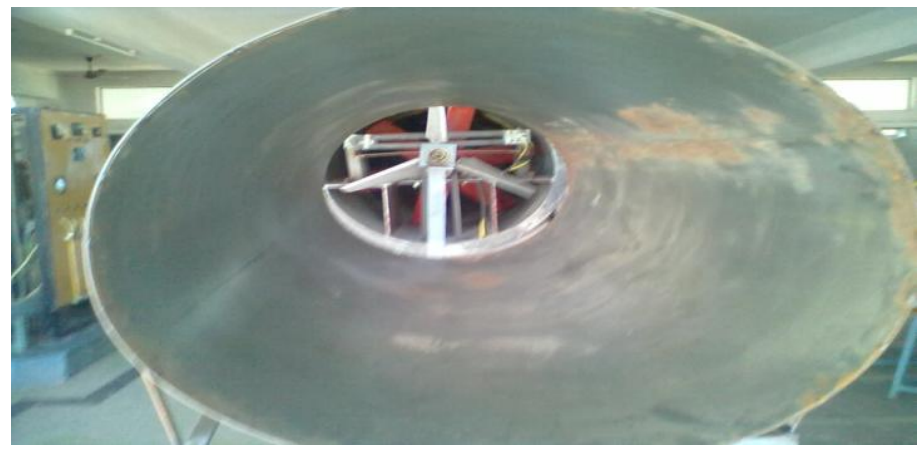

Figure7. Abut View Of Rear End Of Diffuser Augmentation And Combination With Convergence 


\section{Conclusions}

When used only convergent nozzle give power coefficient is 0.3392 . As soon as used only diffuser augmentation give power coefficient is 0.226 . Power coefficient is more, when using both combinations compared just before other modifications. The both combination gives power coefficient is 0.411 .

\section{References}

[1]. Oman, R.A., Foreman, K.M., Gilbert, B.L. 1975, "A Progress Report on the Diffuser Augmented Wind Turbine" Workshop on Wind Energy Conversion Systems Washington DC, USA p. 829-826

[2]. G.D. Rai, Non-conventional Energy Sources, Dhanpat Rai and Sons, New Delhi, 1998.

[3]. Phillips, DG; Flay, RGJ and Nash, TA. Aerodynamic Analysis and Monitoring of the Vortex 7 Diffuser-augmented Wind Turbine.

[4]. D. Mukherjee- 2007 - Renewable energy sources 271-285, 20(2001).

[5]. Mechanical Engineering - Free E-Books - E-Books Directory www.e-booksdirectory.com > Engineering

[6]. K.M. Mital, Non-conventional Energy Sources

[7]. India Wind energy Associations http://www.inwea.org/

[8]. Web site of American wind energy association (http://www.awea.org)

[9]. www.ascent- journals.com

[10]. www.project paradise.com 